\title{
Coronary vessel development requires activation of the TrkB neurotrophin receptor by the Wilms' tumor transcription factor Wt1
}

\author{
Nicole Wagner, ${ }^{1,5}$ Kay-Dietrich Wagner, ${ }^{1,5}$ Heinz Theres, ${ }^{2}$ Christoph Englert, ${ }^{4}$ Andreas Schedl, ${ }^{1,7}$ \\ and Holger Scholz ${ }^{3,6}$ \\ ${ }^{1}$ INSERM U636, Centre de Biochimie, Faculté des Sciences, 06108 Nice, France; ${ }^{2}$ Medizinische Klinik und Poliklinik, and \\ ${ }^{3}$ Institut für Physiologie, Charité-Universitätsmedizin Berlin, 10117 Berlin, Germany; ${ }^{4}$ Institute of Molecular Biotechnology, \\ 07745 Jena, Germany
}

The formation of intramyocardial blood vessels is critical for normal heart development and tissue repair after infarction. We report here expression of the Wilms' tumor gene-1, Wt1, in coronary vessels, which could contribute to the defective cardiac vascularization in $W t 1^{-/-}$mice. Furthermore, the high-affinity neurotrophin receptor TrkB, which is expressed in the epicardium and subepicardial blood vessels, was nearly absent from Wt1-deficient hearts. Activation of Wt1 in an inducible cell line significantly enhanced TrkB expression. The promoter of NTRK2, the gene encoding TrkB, was stimulated $\sim 10$-fold by transient cotransfection of a Wt1 expression construct. The critical DNA-binding site for activation of the NTRK2 promoter by Wt1 was delineated by DNase I footprint analysis and electrophoretic mobility shift assay. Transgenic experiments revealed that the identified Wt1 consensus motif in the NTRK2 promoter was necessary to direct expression of a reporter gene to the epicardium and the developing vasculature of embryonic mouse hearts. Finally, mice with a disrupted Ntrk2 gene lacked a significant proportion of their intramyocardial blood vessels. These findings demonstrate that transcriptional activation of the TrkB neurotrophin receptor gene by the Wilms' tumor suppressor Wt1 is a crucial mechanism for normal vascularization of the developing heart.

[Keywords: Vasculogenesis; neurotrophin receptor; transcription factor; transgenic mice; Wilms' tumor; epicardium]

Received April 7, 2005; revised version accepted August 25, 2005.

The formation of new blood vessels in the heart is essential for both normal cardiac development in the embryo and tissue repair after myocardial infarction in the adult. Early coronary vascularization is established by the recruitment of endothelial progenitor cells to the sites of new blood-vessel configuration, a process known as vasculogenesis (for review, see Reese et al. 2002; Luttun and Carmeliet 2003). Another critical step in the development of the coronary vascular system is angiogenesis, the sprouting of new capillaries from pre-existing vessels (for review, see Morabito et al. 2002; Tojota et al. 2004). The genetic program that controls these processes in the embryonic heart is not well understood.

It is well established that the epicardium plays a critical role during intramyocardial vascularization. The epi-

\footnotetext{
${ }^{5}$ These authors contributed equally to this work.

Corresponding authors.

${ }^{6}$ E-MAIL holger.scholz@charite.de; FAX 49-30-450-528972.

${ }^{7}$ E-MAIL schedl@unice.fr; FAX 33-04-92-07-6402.

Article and publication are at http://www.genesdev.org/cgi/doi/10.1101/ gad.346405.
}

cardium is a mesothelial tissue, which covers the outer surface of the heart and provides the source of coronary vascular precursor cells (Männer et al. 2001; Pérez-Pomares et al. 2002; Olivey et al. 2004). Hence, a failure of normal formation of the epicardium may impair intramyocardial vessel development. The product of the Wilms' tumor gene-1, Wt1, is among the factors that are necessary for an intact epicardium (Kreidberg et al. 1993; Moore et al. 1999|. Wt1 molecules comprise a group of zinc finger proteins that can function as transcription factors (Rauscher III 1993; Lee et al. 1999). Additionally, some Wt1 forms, which have a three-amino-acid splice insertion (lysine, threonine, and serine; KTS) in their C-terminal zinc finger domain (Haber et al. 1991), have been implicated in mRNA processing (Englert et al. 1995b; Larsson et al. 1995; Ladomery et al. 1999). Beside other abnormalities (Kreidberg et al. 1993; Herzer et al. 1999; for review, see Scharnhorst et al. 2001), mice with targeted inactivation of Wt1 exhibit a partial defect of the epicardium, defective cardiac vascularization, and reduced thickness of the myocardium (Kreidberg et al. 1993; Moore et al. 1999). The mutant embryos are lethal 
after mid-gestation, presumably due to a contractile failure of their hypoplastic hearts.

Wt 1 expression in adult hearts is normally restricted to the epicardial cells (Kreidberg et al. 1993; Moore et al. 1999). However, we have recently found that vascular endothelial and smooth muscle cells in the heart also expressed $\mathrm{Wt} 1$ in response to regional tissue ischemia and systemic hypoxia (Wagner et al. 2002a). De novo expression of Wt1 in the myocardial vasculature was limited to the infarct border zone, coincident with local up-regulation of provasculogenic molecules (Wagner et al. 2002a). Thus, epicardium-derived vascular cells in the heart may retain their capacity to express $\mathrm{Wt} 1$, which becomes relevant under conditions that promote the growth of new blood vessels. Whilst these findings sug-
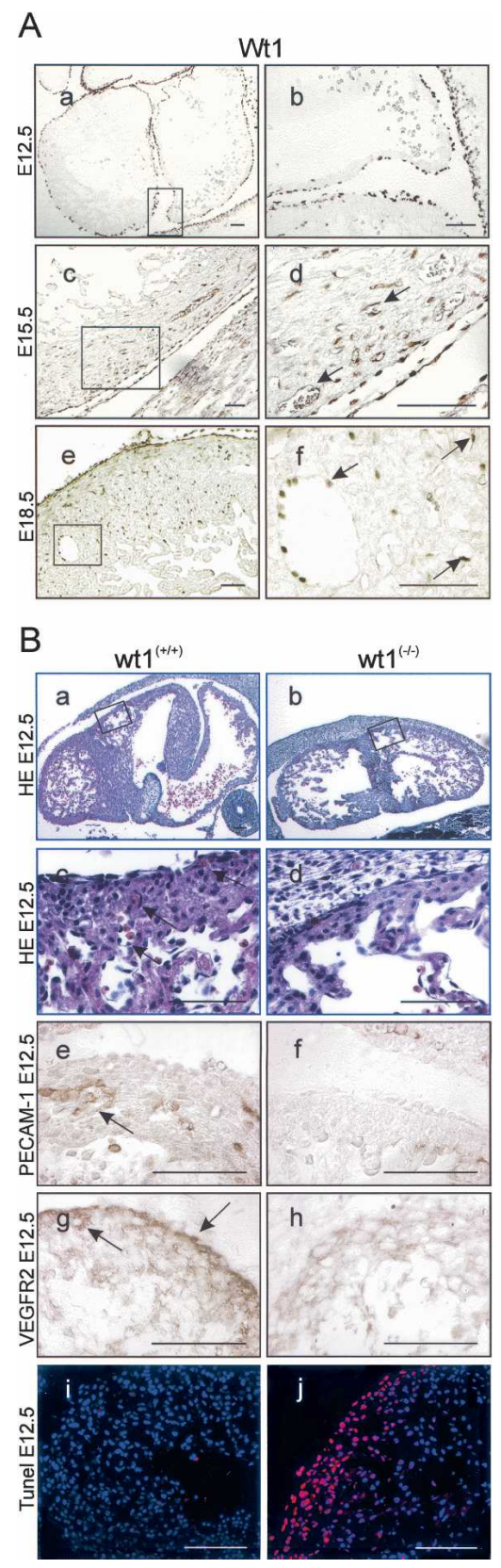

gested a relationship between $\mathrm{Wt1}$ and myocardial blood-vessel development, it remained unclear whether Wt1 is indeed necessary for normal vascularization of the heart, as it would be predicted from its previously recognized role in epicardium formation (Kreidberg et al. 1993; Moore et al. 1999).

Our present study served a twofold purpose. Firstly, we aimed to establish a role for $\mathrm{Wt} 1$ in the development of the myocardial vasculature. Secondly, we wanted to identify potential downstream effectors of Wt1 in this process. Important clues to the identification of candidate targets of Wt1 during coronary blood-vessel formation may come from a detailed analysis of differentially expressed genes of wild-type and Wt1-deficient mice.

We show here that one of the genes, expressed differentially in the hearts of wild-type and $W t 1^{-/-}$mice is Ntrk2, the gene encoding for the tyrosine kinase type B receptor (TrkB). TrkB is a tyrosine kinase receptor with high affinity for neurotrophin 4/5 (NT4/5) and brain-derived neurotrophic factor (BDNF) (for review, see Dechant 2001; Teng and Hempstead 2004). In addition to other defects, mice with an inactivated BDNF gene had abnormal myocardial capillaries due to endothelial cell apoptosis, suggesting a role for BDNF signaling in the coronary blood-vessel formation (Donovan et al. 2000). We report here that expression of Ntrk2, the gene encoding TrkB, is stimulated by the Wilms' tumor transcription factor, Wt1. Furthermore, transcriptional activation of the TrkB neurotrophin receptor by $\mathrm{Wt} 1$ is a critical mechanism during myocardial blood-vessel formation.

\section{Results}

Wt1 is required for normal blood-vessel formation in the heart

Immunohistochemical analyses were performed to explore whether Wt1 is expressed in the developing blood-

Figure 1. (A) Wt1 expression detected by immunoperoxidase labeling in the developing mouse heart. At E12.5, the earliest time point studied, Wt1 immunoreactivity was restricted to the epicardial cells on the outer surface of the heart. In addition to the epicardium, nuclear Wt1 staining was clearly seen in the myocardial blood vessels (arrows) at E15.5 and E18.5. (B) Representative HE-stainings of the hearts of wild-type $\left(W t 1^{+/+}\right)$and Wt1-deficient $\left(W t 1^{-/-}\right)$mouse embryos at E12.5 on a C57/BL6 genetic background. Note the subepicardial capillaries in normal hearts (arrows in panel $c$ ), which were absent from the $W t 1^{-1-}$-mutant embryos (panel $d$ ). PECAM-1/CD31 immunostaining of vascular endothelial cells in the heart of a wild-type (panel $e$ ) and a Wt1-deficient (panel $f$ ) mouse embryo at E12.5. Absence of a vascular PECAM-1 signal indicates a reduction of myocardial blood vessels in the $W t 1^{-1-}$ mutant heart. The results shown are the representative findings from three wildtype and Wt1-deficient embryos that were analyzed. Bars, 100 $\mu \mathrm{m}$. Impaired vascularization of the Wt1-deficient hearts is confirmed by their weaker immunostaining for the type 2 VEGF receptor, flk1, compared with the normal myocardium (panel $h$ vs. panel $g$ ). TUNEL labeling revealed apoptosis of a significant portion of cells in the epicardium and subepicardial tissue of $W t 1^{-1-}$ hearts (panel j), but not in wild-type embryos (panel i). 
vessel system of embryonic hearts. As reported previously (Armstrong et al. 1993; Moore et al. 1999), Wt1 immunoreactivity was initially detected in the developing epicardium of mouse embryos at embryonic day 12.5 (E12.5), the earliest time point studied (Fig. 1A, panels a,b). In addition to the epicardial cells, Wt1 was clearly visible in the coronary vessels at E15.5 and E18.5 (Fig. 1A, panels $\mathrm{c}-\mathrm{f})$. The majority of Wt1-expressing blood vessels were located in the subepicardial zone, but Wt1positive capillaries could also be found in the deeper myocardium (Fig. 1A, panels c-f). To investigate whether $\mathrm{Wt} 1$ is necessary for normal myocardial vascularization, we initially compared the morphology of wild-type and Wt1-deficient hearts from embryos on a C57BL/6 genetic background. HE-stainings were performed on three wildtype and Wt1-deficient embryos each. Subepicardial blood vessels were readily detectable in wild-type hearts at E12.5, but were missing in the $W t 1^{-/-}$mutant embryos (Fig. 1B, panels a-d). Immunolabeling of PECAM1/CD31, a marker specific for developing blood vessels (DeLisser et al. 1997), confirmed the HE-stainings. PECAM-1/CD31-positive capillaries could be detected in the heart of wild-type embryos (Fig. 1B, panel e) as well as in heterozygous $\left(W t 1^{+/-}\right)$embryos (data not shown) at E12.5. In contrast, PECAM-1/CD31 immunoreactivity was markedly reduced and could be only detected in endocardial cells in the tissue of embryos that were deficient for $W t 1$ (Fig. 1B, panel f). These results were confirmed by immunostaining of the type 2 VEGF receptor, flk1. In addition to the epicardium and myocytes, flk1 immunoreactivity was detected in the subepicardial capillaries of normal embryos, but was barely seen in $W t 1^{-/-}$hearts except for the myocyte expression (Fig. 1B, panels g,h; Sugishita et al. 2000). Impaired myocardial vascularization in the Wt1 knockout embryos is in agreement with their previously reported epicardial defects (Kreidberg et al. 1993; Moore et al. 1999). Since apoptosis is frequently observed in Wt1-deficient tissues that would normally express Wt1 (Kreidberg et al. 1993; Hammes et al. 2001; Wagner et al. 2002b, 2005), we performed TUNEL-labeling to explore whether programmed cell death may account for disruption of the epicardium in the $W t 1^{-/-}$hearts. Strikingly, a significant number of TUNEL-positive (apoptotic) cells were found in the epicardium and subepicardial region of the $W t 1^{-/-}$ embryos, but not in wild-type hearts (Fig. 1B, panels $i, j$ ).

Embryos with lack of $W t 1$ on a C57BL/6 genetic background die at E12.5 (Kreidberg et al. 1993). To exclude the possibility that the observed defects are caused by a developmental delay rather than a specific action of $\mathrm{Wt} 1$ during cardiac vascularization, we used $W t 1^{-/-}$mice on a MF1 genetic background, which have been reported to survive until end-gestation (Herzer et al. 1999). HE-stainings were performed on two wild-type and two knockout embryos at E15.5 on the MF1 genetic background (Fig. 2a-f). Strikingly, coronary vessels were almost completely missing and the myocardium was dramatically reduced in size in $W t 1^{-/-}$embryos on the MF1 background. The severe reduction of coronary vessels was further confirmed by the dramatically reduced immuno-

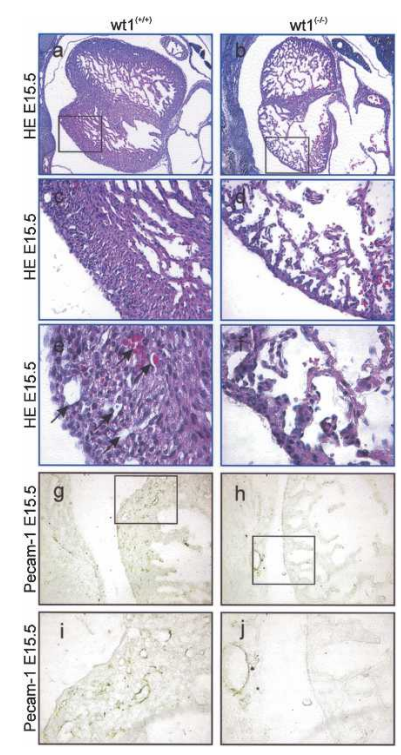

Figure 2. Representative HE-stainings of the hearts of wildtype $\left(W t 1^{+/+}\right)$and $W t 1$-deficient $\left(W t 1^{-/-}\right)$mouse embryos at E15.5 on the MF1 genetic background. Note the developing coronary vessels in normal hearts (arrows in $e$ ), which were nearly absent from the $W t 1^{-/-}$mutant embryos $(f)$ and the severe myocardial hypoplasia in $W t 1^{-/-}$embryos $(b, d, f)$. Absence of a cardiac vascular PECAM-1 signal indicates a reduction of myocardial blood-vessel formation in the $W t 1^{-/-}$mutant hearts when compared with wild-type hearts on the MF1 genetic background $(h, j$ vs. $g, i)$. The results shown are the representative findings from two wild-type and Wt1-deficient embryos that were analyzed. Bars, $100 \mu \mathrm{m}$.

reactivity for PECAM-1/CD31 in the $W t 1^{-/-}$hearts (Fig. 2g-i). In contrast, extra-cardiac PECAM-1/CD31 immunoreactivity could be detected in the embryos deficient for $W t 1$, suggesting a specific role for $W t 1$ in coronary vessel formation. The extreme myocardial hypoplasia observed in the embryos deficient for Wt1 on the MF1 genetic background (Fig. 2a-f) might represent a secondary effect due to the lack of coronary vessel formation, since $W t 1$ expression was never detected in cardiac myocytes (Fig. 1A, panels a-f).

\section{Wt1 stimulates the transcription of the TrkB neurotrophin receptor gene (Ntrk2)}

A major challenge was the identification of novel downstream mediators of $\mathrm{Wt} 1$ during vasculogenesis in the developing heart. For this purpose, a genetic screen to identify genes with differential expression pattern in the hearts of Wt1 knockout embryos and wild-type littermates was performed (K.D. Wagner, N. Wagner, and H. Scholz, unpubl.). One of the genes, which we found to be expressed differentially, was Ntrk2, the gene encoding for TrkB. Hence, we reasoned that the BDNF/TrkB signaling pathway may act downstream of Wt1 to promote the formation of myocardial blood vessels. To verify the findings from the genetic screen, we performed immunostaining and real-time RT-PCR for TrkB in Wt1-defi- 
cient and wild-type hearts. The TrkB protein could be visualized in the epicardium and subepicardial blood vessels of normal embryos at E12.5 and E15.5 (Fig. 3A, panels a,c). In contrast, $\operatorname{TrkB}$ immunoreactivity was much weaker in the Wt1 knockout hearts (Fig. 3A, panels $b, d)$. The use of real-time RT-PCR enabled us to distinguish between two types of TrkB receptors, which differ in their intracellular tyrosine kinase domains (Klein et al. 1989, 1990). Both TrkB receptor variants, one with the full-length tyrosine kinase domain (TrkB+TK), and a second receptor subtype with a truncated intracellular signaling motif (TrkB-TK), were significantly reduced in the $W t 1^{-/-}$hearts (Fig. 3B). In fact, 65 PCR cycles were necessary to detect transcripts for both TrkB receptor types in the Wt1 knockout hearts. Double-immunolabeling was performed to test for an overlapping expression pattern with $\mathrm{Wt1}$ as a prerequisite for direct regulation of $\operatorname{TrkB}$ by $\mathrm{Wt} 1$. We analyzed a total of 27 tissue sections from nine different embryos between 11.5 and $18.5 \mathrm{~d}$ post-coitum (dpc). Notably, Wt1 and TrkB shared an overlapping pattern in the developing

A
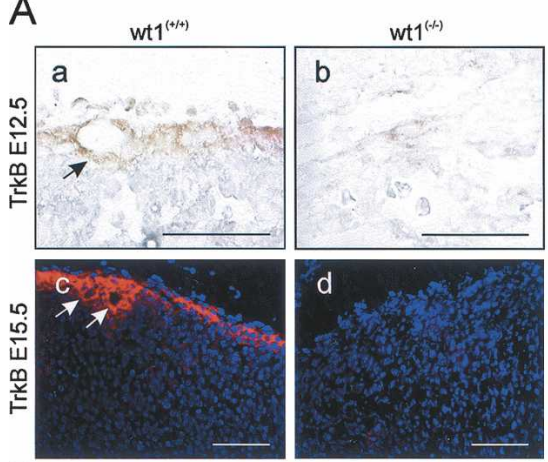

B

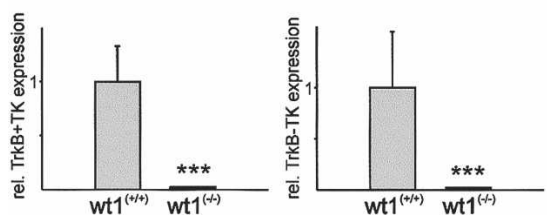

Figure 3. (A) Immunodetection of the TrkB neurotrophin receptor in the hearts of wild-type and Wt1-deficient mouse embryos at E12.5 and E15.5. (Panels $a, c$ ) As reported earlier by others (Donovan et al. 2000), TrkB was expressed in the developing epicardium and myocardial capillaries of normal hearts. (Panels $b, d)$ In contrast, TrkB immunoreactivity was barely detectable in the $\mathrm{Wt1}^{-/-}$mutant hearts. The stainings are representative for the tissue samples that were analyzed from three wild-type and $W t 1^{-1-}$ embryos each at E12.5 and two animals each at E15.5. (B) Real-time RT-PCR to assess TrkB expression in the hearts of wild-type and Wt1-deficient embryos at E12.5. Different primer pairs were selected to detect two alternative $\operatorname{Trk} B$ transcripts: one encoding the full-length receptor with the intracellular tyrosine kinase domain $(+\mathrm{TK})$, and a second TrkB receptor type that lacks the tyrosine kinase motif (-TK). TrkB mRNA was normalized for GAPDH transcripts. Normalized TrkB levels in wild-type hearts $\left(W t 1^{+/+}\right)$were taken as 1 . Realtime RT-PCR was performed on RNA samples that were obtained from four wild-type and five $W t 1^{-/-}$embryos.

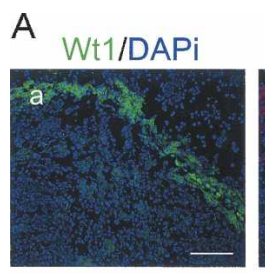

TrkB/DAPi
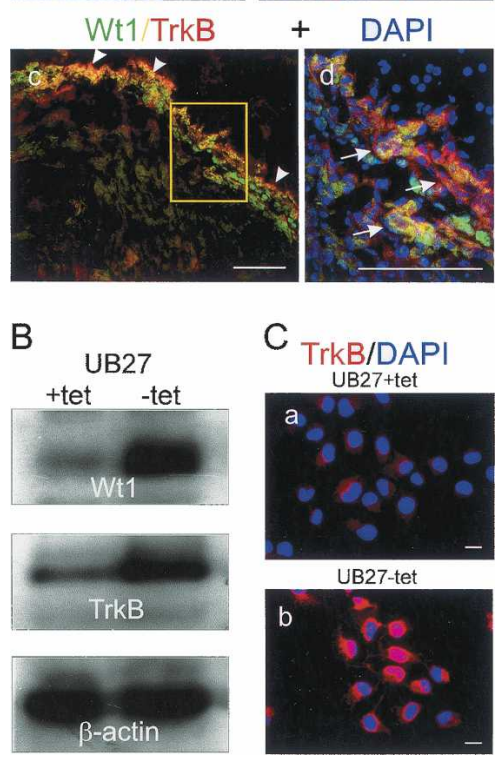

$C_{\text {TrkB/DAPI }}$
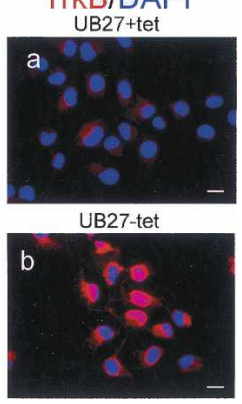

Figure 4. (A) Representative double immunofluorescent labeling of Wt1 (green) and the TrkB receptor (red) in the heart of a mouse embryo at E12.5. (Panels $c, d$ ) The two proteins show an overlapping distribution in the developing epicardium (arrowheads) and subepciardial capillaries (arrows), which becomes evident by the yellow fluorescence signal upon merging both images. Counterstaining of the nuclei was performed with Dapi. Bars, $100 \mu \mathrm{m}$. (B) Western blot demonstrating Wt1, TrkB, and $\beta$-actin proteins in a stable osteosarcoma cell line (clone UB27) with inducible expression of Wt1 (Englert et. al. 1995a). The cells were grown in the presence of tetracycline $(+$ tet) to suppress $\mathrm{Wt} 1$. Note that removal of tetracycline from the culture medium (-tet) enhanced the expression of Wt1 and TrkB without changes in $\beta$-actin. $(C)$ Immunocytochemical staining of TrkB in UB27 cells that were cultured either in the presence (+tet) or absence (-tet) of tetracycline. (B) Omission of tetracycline from the culture medium to stimulate $\mathrm{Wt} 1$ expression lead to an up-regulation of TrkB in the plasma membranes of most UB27 cells. Bars, $10 \mu \mathrm{m}$.

myocardial blood vessels and epicardium as indicated by the representative immunostainings in Figure 4A. Next, we examined whether variable Wt1 expression levels in cultured cells would result in similar changes of TrkB. For this purpose we made use of a stable osteosarcomaderived cell line (U2OS cells), which expresses the Wt1(-KTS) splice variant under control of a tetracyclinesensitive promoter (Englert et al. 1995a). This Wt1 form, which lacks a three-amino-acid splice insertion (KTS) in its C-terminal zinc finger domain (Haber et al. 1991), has been proven to function as a transcription factor (Englert et al. 1995a; Lee et al. 1999). Wt1 mRNA and protein levels in the inducible cell line were elevated significantly upon removal of tetracycline from the culture me- 
dium (Fig. 4B). Up-regulation of Wt1(-KTS) was associated with a more than fourfold increase in TrkB protein expression without changes in $\beta$-actin (Fig. 4B). This increase in TrkB was not due to subclonal variations, but was detected by immunocytochemical staining in the majority of the induced cells (Fig. 4C), indicating that Wt1 could stimulate the expression of TrkB. We therefore addressed the question of whether Wt1 would activate the promoter of the NTRK2 gene directly. For this purpose, $\mathrm{a} \approx 2.3$-kb sequence, which carried the predicted promoter of the NTRK2 gene (NCBI accession no. AF410902) was cloned and ligated into the pGL2 basic reporter plasmid. The luciferase reporter was transiently transfected into HeLa and U2OS cells along with Wt1 expression constructs and a CMV- $\beta$-gal plasmid for normalization of transfection efficiencies. Cotransfection of Wt1(-KTS) stimulated the activity of the NTRK2 promoter approximately sixfold- and 10-fold in HeLa and U2OS cells, respectively (Fig. 5A). Wt1(+KTS), a splice variant that appears to play a role in mRNA processing rather than transcriptional regulation (Englert 1995b; Larsson et al. 1995; Ladomery et al. 1999) had some effect, which, however, was not statistically significant in both cell lines (Fig. 5A). To narrow down the region con- taining cis-acting element(s) for transactivation of the NTRK2 promoter by $\mathrm{Wt} 1$, we cotransfected several reporter constructs with different $5^{\prime}$-truncations in U2OS cells. The transfection experiments yielded $a \approx 600$-base pair (bp) sequence, flanked by KpnI and PstI restrictions sites and located $\sim 800$ bp upstream of the transcription initiation site, which was required for stimulation of the NTRK2 promoter by Wt1 (Fig. 5B). We next performed DNase I footprint analysis to demonstrate that Wt1(-KTS) could bind to a single GC-rich motif within this sequence (Fig. 5C). Physical interaction of Wt1 with this element was confirmed by electrophoresis mobility shift assay (Fig. 5D). A strong retardation band was detected when the oligonucleotide from the NTRK2 promoter was incubated with the Wt1(-KTS) protein. The Wt1(+KTS) form did also bind to the identified element, albeit with much lower affinity. Introducing a trinucleotide mutation (5'-CTAAAA-3') into the core sequence (5'-CTCCCA-3') of the oligonucleotide completely abolished binding of the Wt1(-KTS) protein (Fig. 5D). The previously established Wt1 consensus element from the vitamin D receptor promoter was used as a positive control in the gel-shift experiments (Maurer et al. 2001; Wagner et al. 2001).

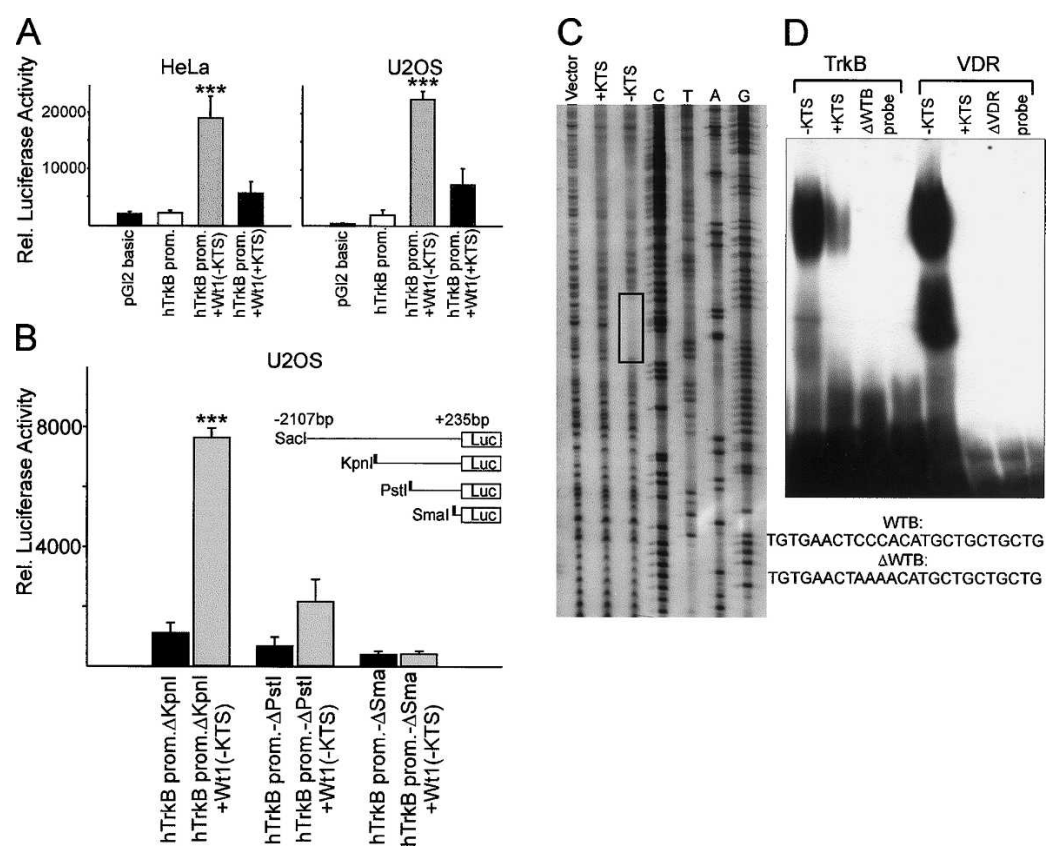

Figure 5. (A) Activation of the promoter of NTRK2, the gene encoding the TrkB neurotrophin receptor, by the Wt1(-KTS) protein. A $\approx 2.3$-kb DNA sequence carrying the promoter of the NTRK2 gene (NCBI accession no. AF410902) in a luciferase reporter plasmid (pGL2basic) was transiently cotransfected into HeLa and U2OS cells together with Wt1(-KTS) and Wt1(+KTS) expression constructs. Luciferase activities were measured in the cell lysates after $48 \mathrm{~h}$ and normalized for the activity of cotransfected $\beta$-galactosidase. Normalized luciferase activities were increased approximately sixfold and 10-fold in HeLa and U2OS cells, respectively, by cotransfection of $\mathrm{Wt} 1(-\mathrm{KTS})$. The Wt1(+KTS) protein, which has been implicated in mRNA processing rather than transcriptional regulation (Englert 1995b; Larsson et al. 1995; Ladomery et al. 1999), had no statistically significant effect. Shown are means \pm S.E.M. from 10 transfection experiments, each performed in duplicate in U2OS cells, and 20 transfection experiments in HeLa cells. $P<0.05$ was considered statistically significant (ANOVA with Bonferroni-test as posthoc test). (B) Effect of cotransfected Wt1(-KTS) on the activity of different NTRK2 promoter constructs with variable lengths in U2OS cells. Various $5^{\prime}$-truncations were generated by restriction digest of the original NTRK2 reporter construct with KpnI, PstI, and SmaI, respectively. A $\approx 600$-bp sequence, flanked by KpnI and PstI restrictions sites and located $\sim 800$ bp upstream of the transcription start site was required for stimulation of the NTRK2 promoter by Wt1(-KTS). Data are the means \pm S.E.M. from 10 transfection experiments performed as duplicates. $P<0.05$ was considered statistically significant (ANOVA with Bonferroni-test as post-hoc test). $(C, D)$ DNase I footprint analysis $(C)$ and electrophoretic mobility shift assay (EMSA) (D) demonstrating binding of the Wt1(-KTS) protein to the Wt1-inducible sequence in the NTRK2 promoter. A 625-bp sequence spanning between -821 and $-198 \mathrm{nt}$ relative to the transcription start site of the human NTRK2 gene was amplified by PCR and end-labeled with ${ }^{32} \mathrm{P}$ for DNase I footprint analysis. Note that Wt1(-KTS) protein, but not the Wt1(+KTS) form, bound to a GC-rich consensus motif (boxed area) within this sequence. Physical interaction of Wt1 with the identified oligonucleotide (WTB) was confirmed by EMSA. (D). Introducing a 3-nt mutation into the sequence $(\triangle \mathrm{WTB})$ resulted in a complete loss of Wt1(-KTS) binding. The previously identified Wt1 consensus element from the vitamin D receptor (VDR) promoter served as a positive control (Maurer et al. 2001; Wagner et al. 2001). 
Wagner et al.

The identified Wt1-binding site in the NTRK2 promoter directs expression to the epicardium, myocardial vessels, and other known sites of Wt1

We chose a transgenic approach to investigate whether the identified Wt1-binding site was important for in vivo transcription from the NTRK2 promoter. Transgenic mice were generated, which expressed a lacZ reporter that was driven either by the $\approx 2.3-\mathrm{kb}$ wild-type NTRK2 promoter, or by the NTRK2 promoter with a mutated Wt1(-KTS)-binding motif. Strikingly, in all four transgenic lines lacZ expression under control of the wildtype NTRK2 promoter showed a pattern that was highly similar to the distribution of the endogenous Wt1 gene product. In particular, the NTRK2 promoter directed expression of the transgene to the developing epicardium and myocardial vasculature (Fig. 6), which corresponds to the known expression pattern of TrkB (GenePaint.org, Set: MH132) (Visel et al. 2004). Additional sites of lacZ staining were in the coelomic epithelium and gonads of the embryos (Fig. 6). Both are tissues that have previously been reported to express Wt1 at high levels (Pelletier et al. 1991; Armstrong et al. 1993; Moore et al. 1998) and also express TrkB (GenePaint.org, Set: MH132) (Visel et al. 2004). LacZ-positive cells were also detected at several sites in the CNS, including the retina and ganglia (data not shown) although LacZ expression in the CNS was relatively weak, suggesting that other regula- tory elements are required for neuronal TrkB expression. Most remarkably, in all transgenic lines, mutation of the Wt1-binding motif in the NTRK2 promoter abrogated transgene expression in the developing myocardial vessels and other sites; e.g., the immature gonads that would normally contain Wt1 in wild-type embryos (Fig. 6), but not in ganglia and choroid plexus of the CNS.

\section{The TrkB neurotrophin receptor is required for normal vascularization of the heart}

To explore whether expression of the TrkB neurotrophin receptor would be necessary for normal myocardial blood-vessel growth in vivo, we analyzed the cardiac phenotype of mice with homozygous disruption of the Ntrk2 gene (Klein et al. 1993). Six viable embryos each with the $\mathrm{TrkB}^{-/-}$mutation could be collected from different litters between E12.5 and E18.5. These embryos were compared with their wild-type littermates. In contrast to Wt1-deficient mice, TrkB $B^{-/-}$mutants showed no epicardial defects, indicating that the initial formation of the epicardium does not depend on TrkB expression. However, we observed a marked reduction of developing blood vessels predominantly in the subepicardial region of $\mathrm{TrkB}^{-1-}$ mutant hearts (Fig. $7 \mathrm{a}-\mathrm{h}$ ). Impaired myocardial vascularization in the TrkB-deficient embryos was confirmed by immunolabeling of the type 2 VEGF recep-
A

Figure 6. Transgenic expression of the lacZ reporter under control of $\mathrm{a} \approx 2.3$ - $\mathrm{kb}$ sequence containing the promoter of the NTRK2 gene (hTrkBprom:hsp68:LacZ). Control animals (E12.5) harbored the lacZ cassette without the human NTRK2 promoter sequence as a transgene. A third construct, in which the identified Wt1(-KTS)-binding element had been mutated, was also used (hTrkBprom $\Delta$ WTB:hsp68:LacZ). The wildtype NTRK2 promoter (hTrkBprom:hsp68:LacZ) directed lacZ expression to the developing epicardium and myocardial blood vessels of the transgenic embryos $(A$ [panel $b$ ], $B$ [panels $a, c])$. ( $B$, panel $a$ ) Additional sites of lacZ staining were in the coelomic epithelium (CE) and the gonads $(G)$. Both are tissues that normally express Wt1 in wild-type embryos. $(\mathrm{H})$ Heart. $(B$, panels $b, d)$ No lacZ staining except for the choroid plexus and other regions in the CNS was detected in embryos carrying a transgenic NTRK2 promoter construct, in which the identified Wt1(-KTS)-binding motif (WTB) had been mutated (hTrkBprom $\Delta$ WTB:hsp68:LacZ). Four independent mouse lines were generated for the hTrkBprom:hsp68:LacZ construct and two lines for hTrkBprom $\Delta$ WTB:hsp68:LacZ.

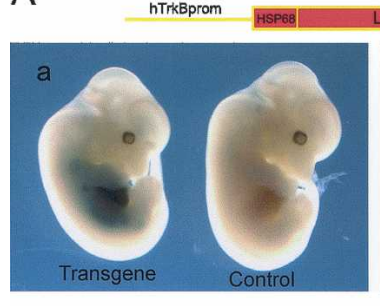

B
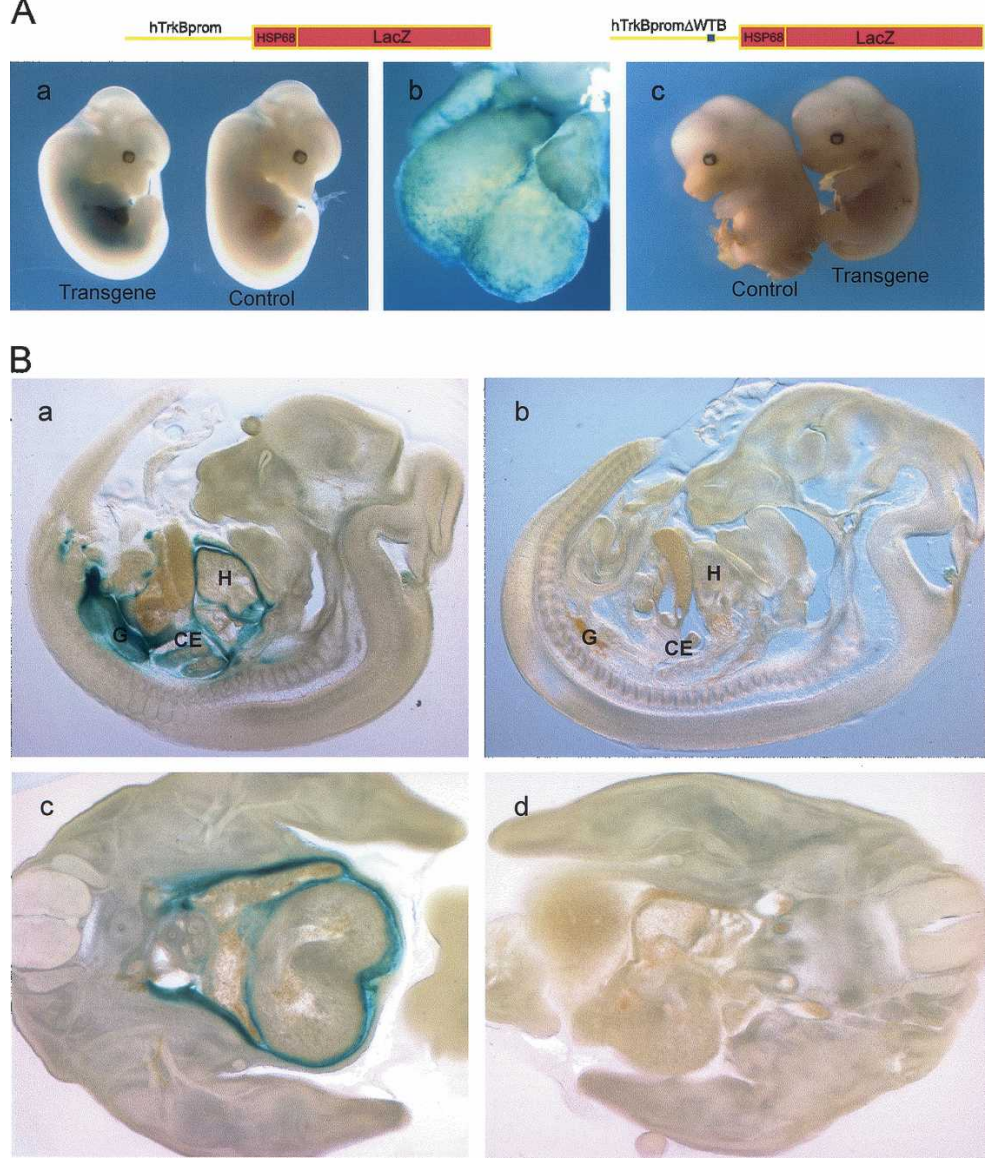
tor (Fig. 7i,j) and of PECAM-1/CD31 (Fig. 7k,1). Interestingly, Wt1-positive cells were present in the epicardium and subepicardial region of the Trk $B^{-/-}$embryos, and single Wt1-expressing cells, though fewer than in normal hearts, were found migrating into the interventricular sulcus of the mutant hearts (Fig. $7 \mathrm{~m}, \mathrm{n}$ ). These findings correlated with an increased number of TUNEL-labeled cells in the subpicardium of embryos with TrkB deficiency (Fig. 7o,p).

\section{Discussion}

Formation of the coronary vessel system is accomplished through a complex series of events that have their origin in the epicardium (Dettman et al. 1998; Vrancken Peeters et al. 1999). The epicardium is a single-layered mesothelium on the outer surface of the heart, which is

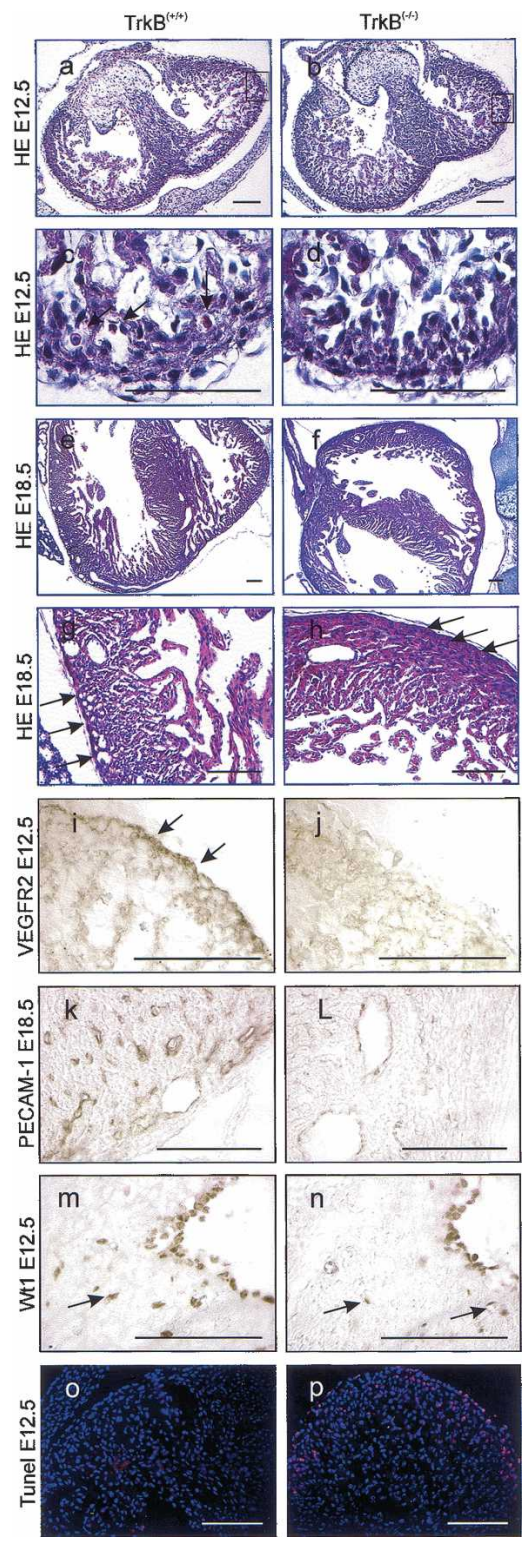

connected to the myocardium by a zone of subepicardial mesenchymal cells (SEMCs). The SEMCs emanate from the epicardial layer by epithelial-to-mesenchymal transition (Mikawa and Gourdie 1996; Pérez-Pomares et al. 1998; Vrancken Peeters et al. 1999) and migrate into the heart, where they give rise to the different cellular components of the blood vessels, including vascular smooth muscle and endothelial cells as well as perivascular fibroblasts (Dettman et al. 1998; Vrancken Peeters et al. 1999). Stabilization of the newly formed capillaries is another critical step during coronary vascularization. In agreement with a previous study (Moore et al. 1999), we report here that the Wilms' tumor suppressor Wt1, which is expressed in the epicardium and SEMCs, is required for normal vascularization of the developing heart.

The Wt1 gene encodes for a group of zinc finger proteins, some of which can function as transcription factors (for review, see Scharnhorst et al. 2001). During heart development in mammals and birds, Wt1 is initially detected in the proepicardial organ (Moore et al. 1999; Carmona et al. 2001) and, subsequently, in the newly formed epicardium and subepicardial mesenchyme (Moore et al. 1999; Carmona et al. 2001). The characteristic pattern of $\mathrm{Wt} 1$ and the results from transgenic studies (Moore et al. 1999) suggested that Wt1 might enable the epicardial cells to flip between a mesenchymal and epithelial state. Accordingly, the hearts of Wt1-deficient embryos contained a significantly reduced number of SEMCs, which also failed to migrate into the myocardium (Moore et al. 1999). While we identified the blood vessels as a novel site of Wt1 expression in the embryonic heart, other investigators could not detect $\mathrm{Wt} 1$ in the developing myocardial vasculature of normal chick embryos (Pérez-Pomares et al. 2002) and of mice with transgenic expression of a lacZ reporter under control of the Wt1 locus (Moore et al. 1999). It is currently unknown whether this apparent discrepancy reflects differences in the expression pattern of Wt1 between mammals and birds, or whether it is due to different experimental conditions and staining procedures. Importantly, we have shown in a recent study that $\mathrm{Wt} 1$ is transcribed de novo in the myocardial vasculature of adult hearts

Figure 7. Histomorphology of the hearts of wild-type embryos at E12.5 and E18.5 $\left(\operatorname{TrkB}^{+/+}\right)$and of littermates with inactivation of Ntrk2, the gene encoding for the TrkB neurotrophin receptor $\left(\operatorname{Trk}_{k} B^{--}\right) \cdot(a-h)$ Note the reduction of subepicardial capillaries (arrows) in $\operatorname{Trk} B$-deficient compared with wild-type hearts, which is revealed by HE-staining of the tissue sections. Impaired vascularization of the $\operatorname{Trk} B^{-/-}$hearts was confirmed by their weaker immunolabeling of VEGFR2 ( $j$ vs. $i)$ and of PECAM-1/CD31, a marker for vascular endothelial cells (1 vs. $k)$. Shown are representative immunostainings from three embryos each. Bars, $100 \mu \mathrm{m}$. Wt1-immunopositive cells were detected, though at a smaller number than in wild-type embryos, in the epicardium and subepicardial tissue of the Trk $B^{-/-}$mutants $(n$ vs. $m) .(m, n)$ From there, the cells migrate into the myocardium, along the interventricular sulcus. TUNEL-labeling revealed more apoptotic cells in the subepicardium of TrkBdeficient than of normal hearts ( $p$ vs. $o$ ). 
after regional tissue ischemia (Wagner et al. 2002a). Together with our previous discovery, the present data testify that Wt1 is a key signal for blood-vessel formation in the heart.

Several lines of evidence suggest that NTRK2, the gene encoding the TrkB neurotrophin receptor, represents a relevant candidate target of $\mathrm{Wt} 1$ during myocardial vascularization. First, TrkB expression was enhanced upon activation of Wt1 in an inducible cell line. Second, TrkB mRNA and protein were significantly reduced in the hearts of Wt1-deficient embryos. Third, Wt1 stimulated the activity of the NTRK2 promoter significantly in transient cotransfection experiments. Fourth, the newly identified Wt1-binding site in the NTRK2 promoter was necessary for transgenic expression of a lacZ reporter in the developing myocardial vasculature and other known sites of Wt1. Finally, like in the $W t 1^{-/-}$mutants, myocardial vascularization was severely disturbed in mouse embryos with inactivated Ntrk2 gene. To our knowledge, abnormal blood-vessel formation in the heart has not been recognized in earlier studies using Ntrk2-deficient mice (Klein et al. 1993).

Considering the overlapping distribution of $\mathrm{Wt} 1$ and TrkB in the epicardium of wild-type embryos, one could argue that the reduction of TrkB in the Wt1-deficient hearts was simply due to epicardial malformation rather than reflecting a regulation of TrkB by $\mathrm{Wt} 1$. However, this possibility appears less likely, because the epicardial defect was incomplete with a substantial portion of the epicardium remaining in the $W t 1^{-/-}$embryos (Moore et al. 1999). On the other hand, TrkB was virtually absent from the Wt1-deficient hearts, suggesting that mechanisms in addition to the loss of epicardial cells are responsible for the lack of TrkB in the mutant hearts. Instead, our findings clearly indicate that Ntrk2, the gene encoding TrkB, is a direct molecular downstream target of $\mathrm{Wt} 1$.

The TrkB receptor is expressed at high levels by central and peripheral neurons, but also by vascular endothelial cells in the developing heart and skeletal muscle (Donovan et al. 1995; Kraemer et al. 1999). It binds the brain-derived neurotrophic factor (BDNF) in addition to the alternate ligands neurotrophin-4/5 (for review, see Dechant 2001; Teng and Hempstead 2004). Abnormal formation of the coronary vessel system has been reported in mice with lack of BDNF (Donovan et al. 2000). BDNF deficiency caused apoptosis of vascular endothelial cells in the heart, leading to destabilization of the myocardial vessel wall and intraventricular hemorrhage (Donovan et al. 2000). Thus, BDNF, through interaction with the TrkB receptor, may function as a survival factor for the vascular endothelium in the developing heart (Donovan et al. 2000). Direct evidence for the angiogenic potential of the BDNF/TrkB signaling pathway has been provided in a recent study demonstrating that adenoviral delivery of BDNF mediated the neovascularization of normal and ischemic tissues in adult mice (Kermani et al. 2005). BDNF may exert its angiogenic effects by two different mechanisms. First, by recruiting TrkB-positive vascular endothelial cells to promote the assembly of new blood vessels (Kermani et al. 2005). And secondly, by the mobilization of TrkB expressing progenitor cells from bone marrow, which will then accumulate at the sites of vascular injury and contribute to vessel formation through the release of angiogenic molecules (Kermani et al. 2005). Our data suggest that Wt1 facilitates these processes by up-regulating TrkB expression in the myocardial vasculature of the developing and adult heart. The latter view is supported by our observation that TrkB expression, similar to Wt1 (Wagner et al. 2002a), was stimulated in the intramyocardial blood vessels of adult rats in response to local tissue ischemia (K.D. Wagner, N. Wagner, and H. Scholz, unpubl.). It remains to be assessed whether the vascular growth-promoting effect of $\mathrm{Wt} 1$ is restricted to the heart, or whether Wt1 can function as a regulator of vasculogenesis also in other tissues. Interestingly, mice with transgenic expression of a mutant $\mathrm{Wt} 1$ protein had dilated glomerular capillaries indicating that $\mathrm{Wt} 1$ may control the expression of growth factors for the formation of microvessels in the kidney (Natoli et al. 2002), although other downstream signaling mechanisms might be responsible since TrkB is not expressed in kidney vessels (Donovan et al. 2000). A wider role for Wt1 in blood-vessel formation is also supported by our previous observation that Wt1 was colocalized with vascular endothelial growth factor (VEGF), a central mediator of vascular growth in various tissues (for review, see Tammela et al. 2005), in the myocardial vasculature of ischemic rat hearts (Wagner et al. 2002a). Notably, VEGF mRNA was increased in a stable osteosarcoma-derived cell line upon induction of Wt1 expression (K.D. Wagner and N. Wagner, unpubl.). It will be an interesting task to investigate whether $\mathrm{Wt1}$ regulates VEGF directly and to reveal the physiological candidate target genes of $\mathrm{Wt} 1$ during vascular formation in the heart and in other tissues.

Considering our present findings and the previously described epicardial phenotype of Wt1-deficient mice (Kreidberg et al. 1993; Moore et al. 1999), we conclude that Wt1 is required at different stages of vascular formation in the heart. During early development, Wt 1 is important for the formation of the epicardium and for the progression from epicardium to SEMCs (Moore et al. 1999), possibly by rescuing epicardial cells from apoptosis and/or by promoting epithelial-to-mesenchymal conversion. Importantly, we could detect no epicardial defects by histomorphological analysis of mouse embryos with $\operatorname{Trk} B$ deficiency. Likewise, the epicardium appeared to be formed normally in mice lacking BDNF, the natural ligand for TrkB (Donovan et al. 2000). Thus, the TrkB/BDNF pathway may be of little importance for Wt1 to fulfill its role in epicardial development. Subsequent expression of $\mathrm{Wt} 1$ in the newly forming myocardial blood vessels suggests a continuous requirement for Wt1 during vascular formation in the heart. Importantly, Wt1-immunopositive cells were seen migrating along the interventricular sulcus from the epicardial layer into the myocardium of the TrkB-deficient mice. Thus, despite of an intact epicardium, Wt1 failed to promote normal coronary vessel formation in the absence of TrkB. In 
conclusion, acting as a survival factor for cells forming the coronary vessels, TrkB is required for Wt 1 to accomplish its role in coronary vascularization. Our results demonstrate that, among other mechanisms, activation of TrkB expression by the Wilms' tumor transcription factor is a critical step for the integrity of the developing coronary vessel system.

\section{Materials and methods}

\section{Animals}

Mouse breeding pairs (C57BL/6 strain), which were heterozygous either for Wt1 or for Ntrk2 (TrkB), were obtained from the Jackson Laboratory and genotyped by PCR according to the protocols provided. The Wt1 mutation was crossed into the MF1 genetic background as described previously (Herzer et al. 1999). Wt1 knockout embryos were obtained at the expected frequency whereas most of the $\mathrm{TrkB}^{-/-}$mice died before mid-gestation.

Transgenic animals were generated by pronuclear microinjection into fertilized mouse oocytes according to established procedures (Moore et al. 1998). Superovulation was performed using the $\mathrm{F} 1$ generation of $\mathrm{CBA} \times \mathrm{C} 57 \mathrm{~B} 6$ crosses (Charles River). Transgenic animals were identified by Southern Blot and by PCR using the following primers: 5 -CCCATTCGCATCTAA CAAGG-3' (TrkB-LacZ forward), 5'-TGACTCTTTCACAAG GGTTGC-3' (TrkB-LacZ reverse). Mice carrying the transgene were crossed and fosters were sacrificed at E12.5 (the day of vaginal plug was considered E0.5). LacZ staining was performed on whole embryos according to the protocol by Hogan (Hogan et al. 1994) as described in detail elsewhere (Wagner et al. 2004).

\section{Cell culture}

U2OS osteosarcoma cells (ATCC HTB-96) and HeLa cells (ATCC CCL-2) were obtained from the American Type Culture Collection (ATCC) and grown as described (Wagner et al. 2003, 2004). Stable U2OS cells (clone UB27) with the tetracycline repressible Wt1(-KTS) form were grown as described (Englert et al. 1995a).

\section{Cell transfection experiments and reporter gene assays}

U2OS and HeLa cells at $\sim 60 \%$ confluence were transfected in $60-\mathrm{mm}$ tissue culture plates with the use of the Fugene 6 reagent (Roche Diagnostics). Reporter constructs $(0.5 \mu \mathrm{g})$ together with $0.25 \mu \mathrm{g}$ of a cytomegalovirus (CMV)-driven $\beta$-galactosidase plasmid and $1.25 \mu \mathrm{g}$ of the expression constructs encoding different Wt 1 forms were transiently cotransfected as described in detail elsewhere (Wagner et al. 2003, 2004). The results shown are averages of 10 transfection experiments, each performed in duplicate for U2OS cells, and 20 transfection experiments for HeLa cells. $P<0.05$ was considered significant (ANOVA with Bonferroni-test as post-hoc test).

\section{Plasmids}

NTRK2 promoter constructs: A bacterial artificial chromosome (BAC) carrying the human gene for the TrkB neurotrophin receptor (NTRK2) (NCBI accession no. AL390777) was obtained from the German Resource Center for Genome Research (clone RP11-301F14). The identity of the DNA clone was verified by restriction digest followed by Southern blot hybridization (Wagner et al. 2002b). $\mathrm{A} \approx 2.3$-kb SacI restriction fragment, which contained the predicted promoter of the NTRK2 gene between $-2107 \mathrm{bp}$ and $+235 \mathrm{bp}$ relative to the transcription start site, was ligated into the SacI site of the pGL2basic reporter plasmid (Promega). This construct was assigned as pTrkBprom and its identity verified by dideoxy sequencing of both strands. Shorter promoter constructs were obtained by restriction digest of pTrkBprom with KpnI, PstI, and SmaI, respectively. The resulting constructs contained genomic DNA sequences starting at -968 bp $(\Delta \mathrm{KpnI}),-368 \mathrm{bp}(\Delta \mathrm{PstI})$, and $+174 \mathrm{bp}$ upstream of the transcription initiation site of NTRK2.

LacZ transgenic constructs: The $\approx 2.3-\mathrm{kb}$ SacI restriction fragment with the predicted promoter of the NTRK2 gene was blunt-end ligated into the flushed PstI site of a lacZ reporter plasmid as recently described for the NPHS1 promoter sequence (Wagner et al. 2004). The NTRK2-lacZ cassette was released from the vector backbone by restriction digest before microinjection into fertilized mouse oocytes.

\section{Real-time RT-PCR}

RT-PCR was performed with $2 \mu \mathrm{g}$ of total RNA as described elsewhere (Wagner et al. 2004, 2005). Real time PCR was performed on the Light Cycler Instrument (Roche) using the Platinum SYBR Green kit (Invitrogen). The following primers were used for PCR amplification: mouse TrkB-TK (Ntrk2) (NCBI accession no. M33385), 5'-TGCCTCAATGAGAGCAGCAAG-3' (forward primer), 5'-TCCACGGTGAGGTTAGGAGCA-3' (reverse primer); mouse TrkB+TK (NCBI accession no. X17647), 5'-CCTCCACGGATGTTGCTGAC-3' (forward primer), 5'GCAACATCACCAGCAGGCA-3' (reverse primer). Expression was normalized to the individual levels of the housekeeping gene GAPDH (NCBI accession no. BC_001601), 5'-ATTCAAC GGCACAGTCAAGG-3' (forward primer), 5'-TGGATGCAGG GATGATGTTC-3' (reverse primer).

\section{DNase I footprint analysis}

A 625-bp sequence spanning between -821 and -198 nucleotides $(\mathrm{nt})$ relative to the transcription start site of the human NTRK2 gene (NCBI accession no. AF410902) was amplified by PCR from plasmid pTrkBprom using one nonlabeled and one ${ }^{32} \mathrm{P}$ end-labeled primer (forward primer, 5'-CTTAGAGG TACCTGGATG-3'; reverse primer, 5' -CCCCCGAATGATGC TGCAGAATCCG-3'). The PCR product was gel-purified, and footprint analysis with $50 \mu \mathrm{g}$ of either GST, GST-WT1(-KTS), or GST-WT1(+KTS) was performed as reported recently for the promoter of NPHS1, the gene encoding nephrin (Wagner et al. 2004).

\section{Electrophoretic mobility shift assays}

Electrophoretic mobility shift assays were carried out with purified recombinant GST-Wt1 protein as described in detail elsewhere (Wagner et al. 2003). The following double-stranded oligonucleotide (WTB), which is contained within the Wt1-inducible TrkB promoter $(-720$ to $-699 \mathrm{bp})$, was selected based on the DNase I footprint results; i.e., 5'-TGTGAACTCCCACATGC TGCTG-3' . A trinucleotide mutation was designed into the oligonucleotide to test for the specificity of Wt1 binding (WT $\Delta \mathrm{B})$ : 5'-TGTGAACTAAAACATGCTGCTG-3'. A 21-bp DNA sequence including the previously identified Wt1(-KTS)-binding site from the vitamin D receptor gene promoter $\left(5^{\prime}\right.$-TGAACT TAGTGGGCGTGGTTG-3') served as positive control (Maurer et al. 2001; Wagner et al. 2001).

\section{SDS-PAGE}

Total cell lysates from subconfluent cultures of U2OS cells (clone UB27) were prepared, electrophoresed, and blotted as de- 
scribed in detail previously (Wagner et al. 2003). The following antibodies were used for immunodetection: polyclonal antiWt1 antibody from rabbit (C-19, catalog no. sc-846, Santa Cruz Biotechnology, 1:100 dilution in PBS, 5\% Blotto, 0.05\% Tween$20)$, monoclonal anti-TrkB antibody from mouse (catalog no. 610101, BD Transduction Laboratories, 1:100 dilution in PBS, $5 \%$ Blotto, $0.05 \%$ Tween-20), goat polyclonal antibody against $\beta$-actin (1:500 dilution in PBS, 5\% Blotto, 0.05\% Tween-20; C-11, catalog no. sc-1615, Santa Cruz Biotechnology), peroxidase-coupled goat anti-rabbit secondary antibody (1:1.000 dilution in PBS, 5\% Blotto, 0.05\% Tween-20; Santa Cruz Biotechnology), and rabbit anti-mouse secondary antibody (1:1.000 dilution in PBS, 5\% Blotto, 0.05\% Tween-20).

\section{Histology and immunohistochemistry}

Morphological studies were performed according to our previously published protocols (Wagner et al. 2002a,b, 2004, 2005). Staged embryos (morning of vaginal plug was considered E0.5) were fixed overnight at $4{ }^{\circ} \mathrm{C}$ in paraformaldehyde (3\% in PBS) and either embedded in paraffin or snap-frozen in prechilled isopentane and then embedded in Tissue-Tek O.C.T. compound (Sakura Finetek).Three-micrometer paraffin sections or $10-\mu \mathrm{m}$ cryostat sections were cut and transferred onto gelatin-coated glass slides. The tissue sections were permeabilized with $0.1 \%$ Triton X-100 in PBS and blocked by incubation for $1 \mathrm{~h}$ in $10 \%$ normal serum (in PBS, $0.1 \%$ Triton X-100, 3\% BSA), which was obtained from the same species as the secondary antibody. An indirect immunofluorescent double-labeling technique was used to mark Wt1 and TrkB expressing cells (Wagner et al. 2002a). For this purpose, the sections were incubated $\left(16 \mathrm{~h}, 4^{\circ} \mathrm{C}\right)$ with primary antibodies each diluted 1:50 in PBS, 0.1\% Triton $\mathrm{X}-100,3 \%$ BSA: polyclonal anti-Wt1 antibody from rabbit (C-19, catalog no. sc-846, Santa Cruz Biotechnology) and monoclonal anti-TrkB antibody from mouse (catalog no. 610101, BD Transduction Laboratories). The reaction products were visualized by incubation ( $1.5 \mathrm{~h}$ at room temperature) with Cy3- and Cy2-conjugates (Wagner et al. 2002a). Counterstaining of the nuclei was done with Dapi. The slides were viewed under an epifluorescence microscope (DMLB, Leica) connected to a digital camera (Spot RT Slider, Diagnostic Instruments) with the Spot software (Universal Imaging Corp.). Alternatively, the tissue sections were stained with a peroxidase technique. To this end, the slides were incubated with monoclonal mouse antiTrkB antibody (1:50 dilution in PBS, $0.1 \%$ Triton $\mathrm{X}-100,3 \%$ BSA; catalog no. 610101, BD Transduction Laboratories), polyclonal anti-Wt1 antibody from rabbit (C-19, catalog no. sc-846, Santa Cruz Biotechnology), polyclonal goat anti-PECAM-1 antibody (catalog no. sc-1506, Santa Cruz Biotechnology), or with polyclonal rabbit anti-VEGFR2 antibody (Zymed no. 36-0900). Subsequently, the antigen detection was performed with Vector M.O.M. immunodetection Kit (Vector Laboratories, catalog no. PK-2200), or for PECAM-1 with a biotinylated anti-goat antibody (Vector Laboratories) for Wt1 and VEGFR2 with a biotinylated anti rabbit antibody (Vector Laboratories), followed by incubation with peroxidase-coupled Streptavidin (Sigma). Visualization was achieved with DAB substrate (Vector Laboratories, catalog no. SK-4100).

\section{TUNEL labeling of apoptotic cells}

Apoptotic cells were detected by TUNEL staining in the hearts of paraformaldehyde-fixed mouse embryos using the In situ Cell Death Detection Kit (Roche Molecular Biochemicals) as described previously for the developing retina (Wagner et al. 2002b). Three tissue sections were analyzed at the indicated time points from three different embryos each either of wildtype, $W t 1^{-/-}$, or $\operatorname{Trk} B^{-/-}$.

\section{Acknowledgments}

The expert technical assistance of F. Ranc, M. Magliano, M. Radjkumar, A. Richter, D. Kruspe, and I. Grätsch is gratefully acknowledged. The Wt1 expression constructs and the U2OS osteosarcoma cells with inducible Wt1 expression were a gift from D. Haber. K.-D.W. and N.W. are recipients of fellowships from EMBO and the Agence nationale de recherches sur le sida (ANRS) (K.D.W.), from the Deutsche Forschungsgemeinschaft (DFG), and INSERM (N.W.). This study was supported in part by grants from the DFG (Eng 280/6-1 and Scho 634/5-1) and the Asssociation pour la Recherche contre le Cancer (\#5198) and the Bundesministerium für Bildung und Forschung (grant nos. NGFN, KGCV1, and 01GS0416).

\section{References}

Armstrong, J.F., Pritchard-Jones, K., Bickmore, W.A., Hastie, N.D., and Bard, J.B. 1993. The expression of the Wilms' tumour gene, WT1, in the developing mammalian embryo. Mech. Dev. 40: 85-97.

Carmona, R., González-Iriarte, M., Pérez-Pomares, J.M., and Muñoz-Chapuli, R. 2001. Localization of the Wilms' tumor protein WT1 in avian embryo. Cell Tissue Res. 303: 173186.

Dechant, G. 2001. Molecular interaction between neurotrophin receptors. Cell Tissue Res. 305: 229-238.

DeLisser, H.M., Christofidou-Solomidou, M., Strieter, R.M., Burdick, M.D., Robinson, C.S., Wexler, R.S., Kerr, J.S., Garlanda, C., Merwin, J.R., Madri, J.A., et al. 1997. Involvement of endothelial PECAM-1/CD31 in angiogenesis. Am. J. Pathol. 151: 671-677.

Dettman, R.W., Denetclaw Jr., W., Ordahl, C.P., and Bristow, J. 1998. Common epicardial origin of coronary vascular smooth muscle, perivascular fibroblasts, and intermyocardial fibroblasts in the avian heart. Dev. Biol. 193: 169-181.

Donovan, M.J., Miranda, R.C., Kraemer, R., McCaffrey, T.A., Tessarollo, L., Mahadeo, D., Sharif, S., Kaplan, D.R., Tsoulfas, P., Parada, L., et al. 1995. Neurotrophin and neurotrophin recpeptors in vascular smooth muscle cells: Regulation of expression in response to injury. Am. I. Pathol. 147: 309-324.

Donovan, M.J., Lin, M.I., Wiegn, P., Ringstedt, T., Kraemer, R., Hahn, R., Wang, S., Ibañez, C.F., Rafii, S., and Hempstead, B.L. 2000. Brain derived neurotrophic factor is an endothelial cell survival factor required for intramyocardial vessel stabilization. Development 127: 4531-4540.

Englert, C., Hou, X., Maheswaran, S., Bennett, P., Ngwu, C., Re, G.G., Garvin, A.J., Rosner, M.R., and Haber, D.A. 1995a. WT1 suppresses synthesis of the epidermal growth factor receptor and induces apoptosis. EMBO $J$. 14: 4662-4675.

Englert, C., Vidal, M., Maheswaran, S., Ge, Y., Ezzel, R., Isselbacher, K.J., and Haber, D.A. 1995b. Truncated WT1 mutants alter the subnuclear localization of the wild-type protein. Proc. Natl. Acad. Sci. 92: 11960-11964.

Haber, D.A., Sohn, R.L., Buckler, A.J., Pelletier, J., Call, K.M., and Housman, D.E. 1991. Alternative splicing and genomic structure of the Wilms' tumor gene WT1. Proc. Natl. Acad. Sci. 88: 9618-9622.

Hammes, A., Guo, J.K., Lutsch, G., Leheste, J.R., Landrock, D., Ziegler, U., Gubler, M.C., and Schedl, A. 2001. Two splice variants of the Wilms' tumor 1 gene have distinct functions during sex determination and nephron formation. Cell 
106: 319-329.

Herzer, U., Crocoll, A., Barton, D., Howells, N., and Englert, C. 1999. The Wilms tumor suppressor gene $\mathrm{Wt} 1$ is required for development of the spleen. Curr. Biol. 9: 837-840.

Hogan, B., Beddington, R., Constantini, F., and Lacy, E. 1994. Staining for $\beta$-galactosidase (lacZ) activity. In Manipulating the mouse embryo, 2nd ed. (eds. A. Nagy et al.), pp. 373-375. Cold Spring Harbor Laboratory Press, Cold Spring Harbor, NY.

Kermani, P., Rafii, D., Jin, D.K., Whitlock, P., Schaffer, W., Chiang, A., Vincent, L., Friedrich, M., Shido, K., Hackett, N.R., et al. 2005. Neurotrophins promote neovascularization by local recruitment of TrkB+ endothelial cells and systemic mobilization of hematopoietic progenitors. J. Clin. Invest. 115: 653-663.

Klein, R., Parada, L.F., Coulier, F., and Barbacid, M. 1989. trkB, a novel tyrosine protein kinase receptor expressed during mouse neural development. EMBO J. 8: 3701-3709.

Klein, R., Conway, D., Parada, L.F., and Barbacid, M. 1990. The trkB tyrosine protein kinase gene codes for a second neurogenic receptor that lacks the catalytic kinase domain. Cell 61: 647-656.

Klein, R., Smeyne, R.J., Wurst, W., Long, L.K., Auerbach, B.A., Joyner, A.L., and Barbacid, M. 1993. Targeted disruption of the trkB neurotrophin receptor gene results in nervous system lesions and neonatal death. Cell 75: 113-122.

Kraemer, R., March, K.L., and Hempstead, B.L. 1999. NGF activates similar intracellular signaling pathways in vascular smooth muscle cells as PDGF-BB but elicits different biological responses. Arterioscler. Thromb. Vasc. Biol. 19: 1041-1050.

Kreidberg, J.A., Sariola, H., Loring, J.M., Maeda, M., Pelletier, J., Housman, D., and Jaenisch, R. 1993. WT-1 is required for early kidney development. Cell 74: 679-691.

Ladomery, M.R., Slight, J., Mc Ghee, S., and Hastie, N.D. 1999. Presence of WT1, the Wilms' tumor suppressor gene product, in nuclear poly $(\mathrm{A})(+)$ ribonucleoprotein. J. Biol. Chem. 274: 36520-36526.

Larsson, S.H., Charlieu, J.P., Miyagawa, K., Engelkamp, D., Rassoulzadegan, M., Ross, A., Cuzin, F., van Heyningen, V., and Hastie, N.D. 1995. Subnuclear localization of WT1 in splicing or transcription factor domains is regulated by alternative splicing. Cell 81: 391-401.

Lee, S.B., Huang, K., Palmer, R., Truong, V.B., Herzlinger, D., Kolquist, K.A., Wong, J., Paulding, C., Yoon, S.K., Gerald, W., et al. 1999. The Wilms' tumor suppressor WT1 encodes a transcriptional activator of amphiregulin. Cell 98: 663673.

Luttun, A. and Carmeliet, P. 2003. De novo vasculogenesis in the heart. Cardiovasc. Res. 58: 378-389.

Männer, J., Pérez-Pomares, J.M., Marcías, D., and MuñozChápuli, R. 2001. The origin, formation, and developmental significance of the epicardium: A review. Cells Tissues Organs 169: 89-103.

Maurer, U., Jehan, F., Englert, C., Hubinger, G., Weidmann, E., DeLuca, H.F., and Bergmann, L. 2001. The Wilms' tumor gene product (WT1) modulates the response to 1,25-dihydroxyvitamin D3 by induction of the vitamin D receptor. $J$. Biol. Chem. 276: 3727-3732.

Mikawa, T. and Gourdie, R.G. 1996. Pericardial mesoderm generates a population of coronary smooth muscle cells migrating into the heart along with ingrowth of the epicardial organ. Dev. Biol. 174: 221-232.

Moore, A.W., Schedl, A., McInnes, L., Doyle, M., HecksherSorensen, J., and Hastie, N.D. 1998. YAC transgenic analysis reveals Wilms' tumor 1 gene activity in the proliferating coelomic epithelium, developing diaphragm, and limb. Mech. Dev. 79: 169-184.

Moore, A.W., McInnes, L., Kreidberg, J., Hastie, N.D., and Schedl, A. 1999. YAC complementation shows a requirement for $\mathrm{Wt} 1$ in the development of epicardium, adrenal gland and throughout nephrogenesis. Development 126: $1845-1857$.

Morabito, C.J., Kattan, J., and Bristol, J. 2002. Mechanisms of embryonic coronary artery development. Curr. Opin. Cardiol. 17: 235-241.

Natoli, T.A., Liu, J., Eremina, V., Hodgens, K., Li, C., Hamano, Y., Mundel, P., Kalluri, R., Miner, J.H., Quaggin, S.E., et al. 2002. A mutant form of the Wilms' tumor suppressor gene WT1 observed in Denys-Drash syndrome interferes with glonerular capillary development. I. Am. Soc. Nephrol. 13: $2058-2067$.

Olivey, H.E., Compton, L.A., and Barnett, J.V. 2004. Coronary vessel development: The epicardium delivers. Trends Cardiovasc. Med. 14: 247-251.

Pelletier, J., Schalling, M., Buckler, A.J., Rogers, A., Haber, D.A., and Housman, D. 1991. Expression of the Wilms' tumor gene WT1 in the murine urogenital system. Genes \& Dev. 5: 1345-1356.

Pérez-Pomares, J.M., Macias, D., Garcia-Garrido, L., and Muñoz-Chapuli, R. 1998. The origin of the subepicardial mesenchyme in the avian embryo: An immunohistochemical and quail-chick chimera study. Dev. Biol. 200: 57-68.

Pérez-Pomares, J.M., Phelps, A., Sedmerova, M., Carmona, R., Gonzalez-Iriarte, M., Muñoz-Chapuli, R., and Wessels, A. 2002. Experimental studies on the spatiotemporal expression of WT1 and RALDH2 in the embryonic avian heart: A model for the regulation of myocardial and valvuloseptal development by epicardially derived cells (EPDCs). Dev. Biol. 247: 307-326.

Rauscher III, F.J. 1993. The WT1 Wilms tumor gene product: A developmentally regulated transcription factor in the kidney that functions as a tumor suppressor. FASEB J. 7: 896-903.

Reese, D.E., Mikawa, T., and Bader, D.M. 2002. Development of the coronary vessel system. Circ. Res. 91: 761-768.

Scharnhorst, V., van der Eb, A.J., and Jochemsen, A.G. 2001. WT1 proteins: Functions in growth and differentiation. Gene 273: $141-161$.

Sugishita, Y., Takahashi, T., Shimizu, T., Yao, A., Kinugawa, K., Sugishita, K., Harada, K., Matsui, H., and Nagai, R. 2000. Expression of the genes encoding vascular endothelial growth factor and its flk-1 receptor in the chick embryonic heart. J. Mol. Cell. Cardiol. 32: 1039-1051.

Tammela, T., Enholm, B., Alitalo, K., and Paavonen, K. 2005. The biology of vascular endothelial growth factors. Cardiovasc. Res. 65: 550-563.

Teng, K.K. and Hempstead, B.L. 2004. Neurotrophins and their receptors: Signaling trios in complex biological systems. Cell. Mol. Life Sci. 61: 35-48.

Tojota, E., Matsunaga, T., and Chilian, W.M. 2004. Myocardial angiogenesis. Mol. Cell. Biochem. 264: 35-44.

Visel, A., Thaller, C., and Eichele, G. 2004. GenePaint.org: An atlas of gene expression patterns in the mouse embryo. Nucleic Acids Res. 32: D552-D556.

Vrancken Peeters, M.P., Gittenberger-de Groot, A.C., Mentink, M.M., and Poelmann R.E. 1999. Smooth muscle cells and fibroblasts of the coronary arteries derive from epithelialmesenchymal transformation of the epicardium. Anat. Embryol. 199: 367-378.

Wagner, K.D., Wagner, N., Sukhatme, V.P., and Scholz, H. 2001. Activation of vitamin $\mathrm{D}$ receptor by the Wilms' tumor gene product mediates apoptosis of renal cells. I. Am. Soc. 
Wagner et al.

Nephrol. 12: 1188-1196.

Wagner, K.D., Wagner, N., Bondke, A., Nafz, B., Flemming, B., Theres, H., and Scholz, H. 2002a. The Wilms' tumor suppressor $\mathrm{Wt} 1$ is expressed in the coronary vasculature after myocardial infarction. FASEB J. 16: 1117-1119.

Wagner, K.D., Wagner, N., Vidal, V.P.I., Schley, G., Wilhelm, D., Schedl, A., Englert, C., and Scholz, H. 2002b. The Wilms' tumor gene Wt1 is required for normal development of the retina. EMBO J. 21: 1398-1405.

Wagner, K.D., Wagner, N., Schley, G., Theres, H., and Scholz, H. 2003. The Wilms' tumor suppressor Wt1 encodes a transcriptional activator of the class IV POU-domain factor Pou $4 \mathrm{f} 2$ (Brn-3b). Gene 305: 217-223.

Wagner, N., Wagner, K.D., Xing, Y., Scholz, H., and Schedl, A. 2004. The major podocyte protein nephrin is transcriptionally activated by the Wilms' tumor suppressor WT1. J. Am. Soc. Nephrol. 15: 3044-3051.

Wagner, N., Wagner, K.D., Hammes, A., Kirschner, K.M., Vidal, V.P., Schedl, A., and Scholz, H. 2005. A splice variant of the Wilms' tumour suppressor Wt1 is required for normal development of the olfactory system. Development 132: 13271336. 


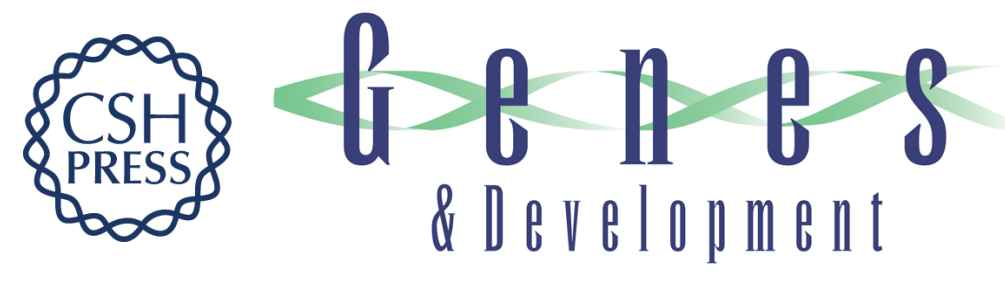

\section{Coronary vessel development requires activation of the TrkB neurotrophin receptor by the Wilms' tumor transcription factor Wt1}

Nicole Wagner, Kay-Dietrich Wagner, Heinz Theres, et al.

Genes Dev. 2005, 19:

Access the most recent version at doi:10.1101/gad.346405

References This article cites 47 articles, 14 of which can be accessed free at: http://genesdev.cshlp.org/content/19/21/2631.full.html\#ref-list-1

License

Email Alerting Receive free email alerts when new articles cite this article - sign up in the box at the top Service right corner of the article or click here.

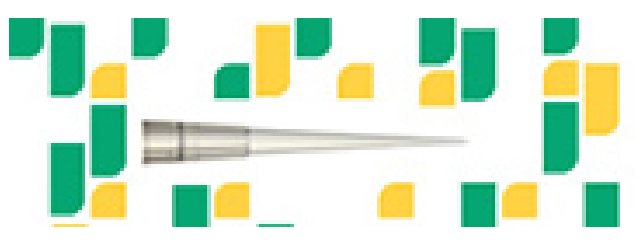

Focused on your science. 